\title{
I. Polnische Juden in Deutschland - eine Randgruppe innerhalb einer Minderheit
}

Die Zahl der zwischen 1933 und 1939 in Deutschland lebenden polnischen Juden kann nicht mit Sicherheit angegeben werden. Entsprechende statistische Angaben stützen sich im wesentlichen auf die Volkszählungen vom Juni 1925 und Juni 1933. Folgt man den Zahlen von 1925, so lebten zum Zeitpunkt dieser Erhebung 499682 Juden in Deutschland, darunter 98747 ausländische Juden (19,8\%), also Juden ohne deutsche Staatsbürgerschaft. Unter den ausländischen Juden wiederum wurden 56480 polnische Juden gezählt. Dies entsprach einem Anteil von $57,2 \%$ an der Gruppe der ausländischen Juden ${ }^{1}$. Zum Zeitpunkt der zweiten Volkszählung im Juni 1933 - also fünf Monate nach der Machtübernahme der Nationalsozialisten hatten bereits einige Tausend polnischer Juden Deutschland verlassen, so daß die Zahl der zu Beginn des Jahres in Deutschland lebenden polnischen Juden nicht angegeben werden kann. Außerdem wurden von der Volkszählung im Juni 1933 nur diejenigen Juden erfaßt, die sich legal in Deutschland aufhielten, nicht jedoch alle tatsächlich in Deutschland lebenden. Insbesondere im Hinblick auf polnische Juden ist die Differenz zwischen beiden Angaben von außerordentlicher Bedeutung: Die geographische Nähe Deutschlands zu Polen sowie die zahlreichen Schwierigkeiten, die Deutschland einer legalen Emigration in den Weg legte, veranlaßten viele Juden dazu, die Grenze illegal zu überschreiten. Jozef Adelson stellte in einer detaillierten Untersuchung die auf deutscher Seite vorhandenen statistischen Angaben den von polnischen Konsulaten in Deutschland geführten Listen polnischer Juden gegenüber. Demnach lebten im Jahre 1932170000 polnische Juden in Deutschland ${ }^{2}$.

Die Differenzen und Unstimmigkeiten zwischen offiziellen deutschen und polnischen Angaben einerseits und den von verschiedenen jüdischen Organisationen vorgenommenen Schätzungen andererseits machen es nahezu unmöglich, auch für die folgenden Jahre die Zahl der in Deutschland lebenden polnischen Juden festzulegen. So schätzten jüdische Organisationen die Zahl der 1936 in Deutschland lebenden polnischen Juden auf 57000 , während die polnischen Vertretungen für dieses Jahr von 70000 polnischen Juden in Deutschland ausgingen ${ }^{3}$. Diese Differenz beruht zweifellos auf dem unterschiedlichen Charakter der Angaben über die Zahl polnischer Juden in Deutschland nach der Machtübernahme der Nationalsozialisten, sicherlich jedoch auch auf der Schwierigkeit, die Zahl der polnischen Juden zu ermitteln, die Deutschland nach dem Januar 1933 den Rücken kehrten. Viele Juden

Adler-Rudel, Ostjuden, S. 165 f.

2 Adelson, Jewish Polish Citizens, S. 97-108. In der zeitgenössischen jüdischen Presse wurde die Zahl der tatsächlich in Deutschland lebenden fremden Juden niedriger angesetzt als in den offiziellen Angaben: C.V.Z., Dic Ostjudenfrage, Nr. 14, 5. 4. 1934.

3 Diese Angabe stützt sich auf einen Bericht des polnischen Konsuls Alfred Wysocki vom 25. 2. 1936 bei: Jonca, Niemiecko Polski, S. 106. 
verließen Deutschland mit Hilfe jüdischer Wohlfahrtsorganisationen, viele andere jedoch wurden von den deutschen Behörden ausgewiesen - ohne jegliche Registrierung und ohne Möglichkeit der Korrektur statistischer Angaben durch offizielle Stellen. Mitte 1938 erhobenen Angaben zufolge lag die Zahl polnischer Juden in Deutschland zu diesem Zeitpunkt zwischen 60000 und 72000 Personen ${ }^{4}$. Nach der Annexion Österreichs durch das Deutsche Reich und der Ausweisung polnischer Juden im Oktober 1938 zählte man in Deutschland Anfang 1939 nur noch wenige Tausend polnischer Juden. Die Statistik spricht von 291426 deutschen Juden, die insgesamt $88,1 \%$ aller in Deutschland lebenden Juden ausmachten. Die Zahl der Juden mit ausländischer Staatsbürgerschaft lag bei 22454 Personen, von denen 15000 polnische Juden waren $(38,3 \%)^{5}$. Berücksichtigt man, daß sich auch unter den Juden ohne Staatsbürgerschaft polnische Juden befanden, steigt die Zahl auf ungefähr 20000 Menschen. Aus diesen Angaben wird deutlich, daß die freiwillige oder erzwungene Emigration sowie die Vertreibung polnischer Juden aus Deutschland zu einer beträchtlichen Verminderung dieser Gruppe noch vor dem Kriege geführt hatten, wodurch der relative Anteil polnischer Juden an der jüdischen Bevölkerung in Deutschland ebenfalls abnahm.

Das Problem, die Zahl der polnischen Juden in Deutschland mit Gewißheit zu bestimmen, ergibt sich jedoch nicht nur aus den Differenzen zwischen den Angaben des polnischen Außenministeriums, der deutschen Behörden und der jüdischen Organisationen, sondern auch durch die Schwierigkeiten, die die Frage aufwirft, wer eigentlich polnischer Jude ist. Nach internationalem Recht galt derjenige als polnischer Jude, der die polnische Staatsbürgerschaft besaß, dessen Herkunft also in jenen österreichisch-ungarischen Gebieten lag, die am Ende des Ersten Weltkrieges zum Gebiet des polnischen Staates erklärt wurden, oder dessen Herkunft in jenen polnischen Gebieten lag, die vor dem Ersten Weltkrieg unter russischer Herrschaft standen, und der sein Anrecht auf polnische Staatsbürgerschaft entsprechend einer Vereinbarung zwischen Rußland und Polen bis zum April 1922 angemeldet hatte ${ }^{6}$. Juden, die ihre Option auf polnische Staatsbürgerschaft nicht verwirklicht hatten oder die im Laufe der zwanziger Jahre die polnische Staatsbürgerschaft gegen die deutsche eingetauscht und diese nach 1933 wiederum verloren hatten, erschienen in der Stastitik nicht als polnische Staatsangehörige, sondern als staatenlos.

Polnische Juden in Deutschland zeichneten sich durch einige charakteristische Merkmale aus. Zwischen den Weltkriegen konzentrierte sich die polnisch-jüdische Bevölkerung in Deutschland vornehmlich in den Großstädten?. Weniger als $15 \%$ aller polnischen Juden lebten in Städten mit weniger als 100000 Einwohnern. In Berlin allein lebten zirka 50\% aller polnischen Juden, viele auch in einigen Städten Sachsens, insbesondere in Leipzig. 8 . Diese Konzentration auf urbane Zentren ent-

4 Adelson, Jewish Polish Citizens, S. 104; Jonca, Niemiccko Polski, S. 106.

5 CAHJP, Inv. 4631, Die Juden und jüdische Mischlinge in Großdeutschland, 17. 7. 1939, Maschinenschrift.

6 Tomaszewski, Polish Diplomats.

7 Adelson, Jewish Polish Citizens, S. 91.

8 Die Angaben über ausländische Juden insgesamt zeigen, daß 74\% sich in Preußen konzentrierten, davon $41,6 \%$ in Berlin; $13 \%$ in Sachsen und $4,7 \%$ in Bayern, wobei sie in diesen Ländern jeweils in den Großstädten lebten; vgl. Maurer, Ausländische Juden, S. 189. 
sprach der Berufsstruktur dieser Gruppe9: Die Mehrheit der polnischen Juden war im Bereich des Handels und Straßenhandels tätig, andere waren in der Kleinindustrie des Textil-, Tabak- oder Kürschnersektors beschäftigt ${ }^{10}$. Die freien Berufe, oft in den Bereichen von Kunst und Unterhaltung, fehlten ebenfalls nicht. Nur wenige polnische Juden arbeiteten in der Schwerindustrie. Diese Industriearbeiter waren vornehmlich in den Kohlenzechen des Ruhrgebiets beschäftigt ${ }^{11}$. Abgesehen von wenigen, die infolge des wirtschaftlichen Aufschwungs in Deutschland Mitte der zwanziger Jahre zu Wohlstand oder gar Reichtum gelangt waren oder im Rohstoffhandel zwischen Deutschland und den Ländern Osteuropas wirtschaftlichen Erfolg gehabt hatten, gehörten polnische Juden mehrheitlich dem Mittelstand und dem unteren Mittelstand an. Die Abhängigkeit des Einkommens der zahlreichen Händler, Straßenhändler und Künstler in den Reihen der polnisch-jüdischen Bevölkerung von Schwankungen des allgemeinen Lebensstandards und allgemeinen Konsumbedürfnissen in der Weimarer Republik führte zu einer erheblichen Verschlechterung der wirtschaftlichen Situation dieser Gruppe nach dem Ausbruch der Wirtschaftskrise in Deutschland Ende der zwanziger Jahre. Die Wohlfahrtsorganisationen der jüdischen Gemeinden, die im Zuge der Masseneinwanderung aus Osteuropa nach Deutschland während des Ersten Weltkrieges ausgebaut worden waren, unterstützten viele der ausländischen Juden, darunter natürlich auch polnische Juden. Folgt man offiziellen Angaben, sieht es so aus, als ob der Anteil polnischer Juden an der Zahl der Wohlfahrtsempfänger ihren Anteil an den Mitgliedern der jüdischen Gemeinden nicht wesentlich überstieg. Die städtische Wohlfahrtsstelle in Berlin unterstützte 1934 insgesamt 8791 deutsche und 2250 ausländische Juden ${ }^{12}$. Doch diese Daten müssen mit Skepsis betrachtet werden. Viele der ausländischen und polnischen Juden hielten sich, wie bereits erwähnt, illegal in Deutschland auf und waren nicht berechtigt, von den deutschen Behörden eine staatliche Unterstützung zu erhalten. Auch unter den legal in Deutschland lebenden Juden wandten sich zudem viele aus Furcht vor einer möglichen Ausweisung nicht an die Wohlfahrtsämter. Auf diesen Umstand weisen auch ähnliche statistische Angaben der jüdischen Wohlfahrtsstellen hin, so etwa des Hilfsvereins. Der relative Anteil polnischer Juden, die im Jahre 1937 Unterstützung erhielten, bewegte sich demnach zwischen 12\% und $14 \%$ gegenüber $76 \%$ Unterstützungsempfängern mit deutscher Staatsbürgerschaft. Dieser Anteil war nicht wesentlich höher als der relative Anteil polnischer Juden an der jüdischen Gesamtbevölkerung in Deutschland ${ }^{13}$.

9 Yahil, Holocaust, S. 27f. Dieser Eindruck entsteht auch aufgrund der zahlreichen Anfragen polnischer Juden in den polnischen Konsulaten in Deutschland seit 1933. Diese Anfragen finden sich im PAAA, Bonn, sowie im AAN in Warschau.

10 Von den ausländischen Juden waren $61 \%$ im Handel und Straßenhandel erwerbstätig. Dieser Prozentsatz entsprach dem Satz der in jenem Sektor beschäftigten deutschen Juden. In Industrie und Handwerk waren $28,1 \%$ aller ausländischen Juden beschäftigt im Vergleich zu 21,7\% der deutschen Juden; siehe Maurer, Ausländische Juden, S. 189. Zum landwirtschaftlichen Sektor siehe: Adelson, Jewish Polish Citizens, S. 99.

11 13,8\% aller ausländischen Juden waren Arbeiter. Dieser Anteil war fast doppelt so hoch wie der Anteil jüdischer Arbeiter unter den deutschen Juden (7,2\%); ebenda.

12 YVA, JM/2866, Auswärtiges Amt an alle diplomatischen und konsularischen Auslandsvertretungen, 4. 11. 1934.

13 SoA, 1325/1/74, Die Zahl der vom Hilfsverein der Juden in Deutschland unterstützten Personen, 1937. 
Im Laufe der zwanziger Jahre blieb die demographische Entwicklung der Juden aus Osteuropa insgesamt und damit auch die der polnischen Juden positiv. 1925 zählten zu der Altersgruppe der bis zu 20jährigen 32\% aller ausländischen Juden in Preußen, gegenüber $23,7 \%$ der preußischen Juden insgesamt; zu der Altersgruppe der über 50jährigen zählten $27,8 \%$ preußische Juden gegenüber $12,9 \%$ ausländischer Juden in Preußen ${ }^{14}$. Die schwierige wirtschaftliche Lage in Deutschland Ende der zwanziger und Anfang der dreißiger Jahre führte zur Emigration zahlreicher junger Menschen, oft auch ganzer junger Familien. Dies trug erheblich zu einer Anhebung des Durchschnittsalters polnischer Juden in Deutschland bei. Die im Sommer 1933 in Deutschland durchgeführte Volkszählung ergab, daß nur mehr 23,3\% aller Juden mit ausländischer Staatsbürgerschaft jünger als 18 Jahre waren ${ }^{15}$.

\section{Polnische Juden: Sündenböcke oder ausländische Schutzbürger}

Im Laufe der Generationen waren Juden aus Osteuropa immer wieder offener Ablehnung oder tätlichem $\mathrm{Haß}$ ausgesetzt ${ }^{16}$. Die Wurzeln dieses Hasses sind zahlreich und vielfältig. Sie werden in der Regel mit der ökonomischen Rolle verknüpft, die osteuropäische Juden als Vermittler zwischen Bauern und Städtern in vorangehenden Jahrhunderten gespielt hatten, aber auch mit dem niedrigen wirtschaftlichen Status dieser Juden sowie mit ihrem Image als Bettler und Kriminelle, das ihnen in Deutschland zugelegt wurde ${ }^{17}$. Im Übergang vom traditionellen zum sogenannten modernen Antisemitismus änderte der $\mathrm{Haß}$ gegen osteuropäische Juden sein Gesicht, verschwand jedoch nicht. So standen osteuropäische Juden in Deutschland seit den siebziger Jahren des 19. Jahrhunderts bis 1933 unverändert im Mittelpunkt antisemitischer Propaganda ${ }^{18}$. Die Massenmigration aus Osteuropa Richtung Westen und die Ankunft von Zehntausenden jüdischer Immigranten in Deutschland vollzog sich gleichzeitig mit der Entwicklung des modernen Antisemitismus, der infolgedessen im Bewußtsein vieler Deutscher und deutscher Juden mit den jüdischen Einwanderern assoziiert wurde. Im „Berliner Antisemitismusstreit“ von 1878/79 - dem zentralen Ereignis bei der Ausbreitung des Antisemitismus in den Kreisen deutscher Intellektueller - warnte der Historiker Heinrich von Treitschke, Professor an der Berliner Universität und Reichstagsabgeordneter, in dem für ihn typischen polemischen Stil, vor der „Schaar (sic!) strebsamer hosenverkaufender Jünglinge (...), deren Kinder und Kindeskinder dereinst Deutschlands Börsen und Zeitungen beherrschen sollen" 19 . Es blieb nicht bei den Worten einer einzelnen, wenn auch zentralen Persönlichkeit. 1881 unterzeichneten mehr als 250000 Deutsche die "Antisemiten-Petition“, in der die Reichsregierung u.a. aufgefordert wurde, die Einwanderung von Juden aus Osteuropa nach Deutschland zu verhin-

14 Yahil, Holocaust, Bd. 1, S. 28.

15 Adelson, Jewish Polish Citizens, S. 99.

16 Zum folgenden vgl. passim: Weiss, Ostjuden.

17 Bernstein, Bettler, S. 53-57.

18 Zur Haltung der Antisemiten gegenüber osteuropäischen Juden siehe: Aschheim, Brothers and Strangers, S. 59-78; ders., Caftan and Cravat.

19 von Treitschke, Unsere Aussichten, zitiert nach: Boehlich, Berliner Antisemitismusstreit, S. 9. 
dern. Zu ersten Ausweisungen polnischer Juden in polnisches Gebiet kam es bereits in den Jahren 1884-1885. Derartige Maßnahmen sollten bis zum Ersten Weltkrieg und auch in der Zeit danach immer wieder zur Anwendung gelangen. Ausweisungen waren das nachdrücklichste Mittel der deutschen Behörden, um die Zahl polnischer Juden auf deutschem Gebiet einzuschränken, und stellten darüber hinaus gern angewandte Strafmaßnahmen und später auch eine Möglichkeit der Machtdemonstration gegenüber dem benachbarten Polen dar. Der Erste Weltkrieg verstärkte in Deutschland allgemein antisemitische Tendenzen, die sich jedoch insbesondere gegen osteuropäische Juden richteten. Die Verhältnisse, mit denen deutsche Soldaten in Osteuropa konfrontiert wurden, erweckten zunächst vielleicht Mitleid und Sympathie, intensivierten letztlich jedoch unter den Soldaten nur Gefühle des Abscheus und der Ablehnung, insbesondere aber das Gefühl des Andersseins gegenüber der jüdischen Bevölkerung Osteuropas. Die gewaltige Furcht vor einer Masseneinwanderung infolge des Weltkriegs und der ausdrückliche Wunsch, jene osteuropäischen Juden, die im Laufe des Krieges als Fremdarbeiter nach Deutschland gebracht worden waren, wieder „loszuwerden“, verstärkten zusätzlich die unter den verschiedenen politischen Körperschaften und innerhalb der deutschen Öffentlichkeit ohnehin herrschende ablehnend-feindliche Haltung gegenüber osteuropäischen Juden. Die in Deutschland gegen Kriegsende und Anfang der zwanziger Jahre herrschende katastrophale wirtschaftliche Lage löste überdies wirtschaftliche Konkurrenzängste aus und öffnete Tor und Tür für die verschiedenartigsten Anschuldigungen: So wurden Juden aus Osteuropa der Schieberei und Wucherei beschuldigt, für arbeitsscheu gehalten und für die Verbreitung von Epidemien verantwortlich gemacht. Die russische Revolution vertiefte die generelle Identifikation Osteuropas mit dem Kommunismus in weiten Kreisen, in denen Juden aus dem Osten nachgesagt wurde, sie unterstützten revolutionäre Tendenzen in Deutschland. Dies war übrigens eine Anschuldigung, die osteuropäische Juden bis in die dreißiger Jahre hinein verfolgte ${ }^{20}$. Die zwanziger Jahre waren insgesamt aber durch eine ambivalente Haltung und Politik gegenüber osteuropäischen Juden gekennzeichnet: einerseits ging man gegen sie mit Verhaftungen und Ausweisungen vor, andererseits gewährte man vielen die deutsche Staatsbürgerschaft.

Rechte Parteien und Organisationen waren es, die in ihrer Propaganda ausländische Juden angriffen und zu einer Gesetzgebung aufriefen, mit der ihre Einwanderung eingeschränkt, ihr Recht auf Freizügigkeit und Berufswahl aufgehoben und ihr Anrecht auf Einbürgerung in Deutschland begrenzt werden sollten. Schon in ihrem Programm von 1920 hatte die NSDAP gefordert, die weitere Einwanderung Nichtdeutscher zu verhindern und diejenigen, die nach dem 2. August 1914 (also nach dem Ausbruch des Ersten Weltkrieges) nach Deutschland gekommen waren, zum „Verlassen des Deutschen Reiches“ zu zwingen ${ }^{21}$. Infolge der Schwäche der Republik und der Zunahme rechter Kräfte konnten sich Parteien des rechten Spektrums 1932 erneut mit der Frage der Einbürgerung von Juden aus Osteuropa beschäfti-

20 Fox sieht in der Furcht vor dem Kommunismus ein zentrales Motiv der anti-jüdischen Politik und der Vernichtungspolitik des Nationalsozialismus. Aus diesem Grunde hält er die Juden aus Osteuropa für einen zentralen Faktor im deutschen Antisemitismus: Fox, Reichskristallnacht.

21 Hilberg, Vernichtung, S. $36 \mathrm{f}$. 
gen $^{22}$. Arbeitslosigkeit und Wirtschaftsnot dienten ihnen als Vorwand, eine weitgehende prinzipielle Ablehnung der Einbürgerungsanträge ausländischer Juden zu fordern. Der preußische Minister des Inneren gab dem Druck nach und leitete den Entwurf eines Gesetzes ein, das eine Einbürgerung von ausländischen Juden nur nach zwanzigjährigem Aufenthalt in Deutschland ermöglichen sollte ${ }^{23}$. Außerdem versuchten rechte Parteien, osteuropäischen Juden in Deutschland die Berufsausübung zu erschweren: Die Tätigkeit jüdischer Ärzte osteuropäischer Herkunft ${ }^{24}$ sollte ebenso eingeschränkt werden wie die Beschäftigung ausländischer jüdischer Schauspieler und Künstler auf staatlichen Bühnen und im Rundfunk. Trotz einer Mehrheit im Reichstag standen derartige Gesetzentwürfe im Widerspruch zur Weimarer Verfassung und konnten keine Gesetzeskraft erlangen ${ }^{25}$. Dieses in den Augen der Rechten bedauerliche Hindernis wurde mit der Machtübernahme der Nationalsozialisten augenblicklich beseitigt.

Schon vor 1933 hatten osteuropäische Juden eine zentrale Rolle in der nationalsozialistischen Propaganda gespielt. Vorrangige Motive waren dabei die Massenimmigration osteuropäischer Juden nach Deutschland infolge des Ersten Weltkriegs, die bolschewistische Revolution und die Entstehung neuer Staaten in Mittelund Osteuropa. Die Einwanderer wurden für alle Schwächen und Krisen in der deutschen Gesellschaft und Wirtschaft verantwortlich gemacht. Um den unterschiedlichen Forderungen „wissenschaftliche“ Gültigkeit zu verleihen, machten Antisemiten reichlich Gebrauch von statistischen Angaben. Die Zunahme der jüdischen Gesamtbevölkerung - trotz Assimilation und negativer Bevölkerungsentwicklung der deutschen Juden - lenkte die Aufmerksamkeit auf die Einwanderer, insbesondere die osteuropäischen, als Ursache dieses Bevölkerungswachstums ${ }^{26}$. Antisemiten behaupteten dann auch, die Mehrheit der jüdischen Bevölkerung in Deutschland stamme ursprünglich aus Osteuropa. Hätte man zur Zeit der Gründung des Deutschen Reiches die Ostgrenzen für Einwanderer geschlossen, dann wäre Deutschland, so die Antisemiten, so gut wie ,judenfrei“. Neben der demographischen Frage widmete sich die Propaganda weiterhin den Gefahren, die der deutschen Gesellschaft und Wirtschaft durch die Präsenz osteuropäischer Juden drohten. Ihnen wurden Geldgier und Gewinnsucht, illegale Wirtschaftsaktivitäten,

22 GStA Merseburg, Rep. 169 D II CF Nr. 4 Bd. 2, Kleine Anfrage Nr. 83 der Deutschnationalen Volkspartei vor dem Preußischen Landtag am 22.6. 1932. Ebenso die Anfrage der NSDAP über die „Infiltration osteuropäischer Juden“ - GStA Merseburg, Anfrage (Nr. 467) vor dem Preußischen Landtag, 22. 11. 1932.

23 Antwort des preußischen Innenministers Severing auf eine Anfrage im preußischen Landtag vom 30. 6. 1932, ebenda, sowie: Hilberg, Vernichtung, S. 38. Hilberg erwähnt darüber hinaus Initiativen von Beamten des preußischen Innenministeriums, Juden eine Namensänderung zu verbieten, wenn diese Namensänderung dazu diene, eine jüdische Herkunft zu verschleiern; ebenda. - Zum propagandistischen Gebrauch jüdischer Namen unter deutschen Antisemiten siehe: Bering, Kampf um Namen, S. $241 \mathrm{ff}$.

24 GStA Merseburg, Kleine Anfrage Nr. 257, Nr. 290, Nr. 592, Nr. 623.

25 Yahil, Holocaust, S. 44; Jïdische Telegraphen Agentur, No. 16, 20. 1. 1933. Dies galt auch für eine Initiative rechter Parteien, den Besitz osteuropäischer Juden, die nach Ausbruch des Ersten Weltkrieges nach Deutschland gekommen waren, zu beschlagnahmen. Tomaszewski, Polish Diplomats, S. 187.

26 Zahlreiche nationalsozialistische Publikationen beschäftigten sich mit diesen Fragen, darunter: Juden in Deutschland; Seraphim, Wanderungsbewegung; Hartenstein, Geschichte Leipzigs; Frecks, Das rassische Erwachen, S. 23; Seifert, Der Osten Europas, S. 32 39. 
Ausbeutung und Zynismus vorgeworfen. Gleichzeitig bezichtigte man sie kommunistischer Tendenzen und der Verbreitung und Förderung revolutionärer Ideen sowie der Untergrabung des Systems ${ }^{27}$. Diese Anschuldigungen standen zwar zueinander im Widerspruch. Die antisemitische Propaganda griff jedoch seit langem zu derartig widersprüchlichen Argumenten, ohne daß dies ihren Einfluß verringert hätte. Die Polemik gegen ausländische Juden sollte zunächst eine antisemitische Politik rechtfertigen, diente aber zugleich als Angriff auf einen alten Gegner - die Sozialdemokratie ${ }^{28}$. Die nationalsozialistische Propaganda machte die liberale Einwanderungspolitik der Sozialdemokraten nach dem Ersten Weltkrieg für die Erschütterung der wirtschaftlichen und politischen Lage Deutschlands Ende der zwanziger Jahre verantwortlich. Nach Ansicht der Nationalsozialisten hatten die Sozialdemokraten die geopolitischen Veränderungen in Europa nach dem Weltkrieg falsch eingeschätzt. Sie hätten die Einwanderung nicht begrenzt oder aufgehalten, da sie an Immigranten aus Osteuropa infolge der politischen Orientierung dieser Personen ein besonderes Interesse gehabt hätten. Die Nationalsozialisten setzten ihre beständigen widersprüchlichen Vorwürfe gegen ausländische Juden ebenso wie die damit verbundenen Schuldzuweisungen an die Adresse der Sozialdemokratie nach 1918 bruchlos fort.

Da die Nationalsozialisten in ihrer Propaganda kontinuierlich in erster Linie osteuropäische Juden angriffen, neigten viele Kreise zu dem Trugschluß, der nationalsozialistische Antisemitismus richte sich überhaupt nur gegen osteuropäische Juden, gegen jüdische Immigranten, nicht aber gegen altansässige deutsche Juden ${ }^{29}$. Cyrus Adler aus dem Führungsgremium des American Jewish Joint Distribution Committee (Joint) meinte drei Tage nach der Machtübernahme der Nationalsozialisten, es sei wohl unmöglich, in Deutschland geborene Personen auszubürgern. Adler ging allerdings davon aus, daß Deutschland zu diesem Zeitpunkt noch immer ein Rechtsstaat war. Doch auch er hatte erkannt, daß jene Juden in Deutschland, die seit dem Krieg aus Rußland, Polen, Ungarn und anderen osteuropäischen Ländern eingewandert und möglicherweise keine deutschen Staatsbürger geworden waren, einer gewissen Gefahr ausgesetzt waren ${ }^{30}$. Auch Bernard Kahn, Koordinator der Joint-Arbeit in Europa und gut mit der deutschen Realität vertraut, war der Ansicht, die Nationalsozialisten könnten die deutschen Juden nicht antasten, wohl aber werde es zu Ausweisungen ausländischer Juden kommen ${ }^{31}$.

27 Friedländer, Nazi-Germany, Bd. 1, S. $41 \mathrm{ff}$.

28 Juden in Deutschland, S. $149 \mathrm{ff}$.; sowie z. B. der Kommentar im Völkischen Beobachter über die Entlassung des Leiters der Ausländerbehörde in Berlin, der nach Ansicht der Nationalsozialisten die Einwanderung vieler ausländischer Juden nach Deutschland gefördert und sie unter den Schutz seiner Behörde gestellt hatte. - Jüdische Telegraphen Agentur, Nr. 43, 21. 2. 1933.

29 Jacob Katz weist darauf hin, daß Jitzchak Breuer aus dem Vorsitz der Agudat Yisrael in Deutschland meinte, nur Juden aus dem Osten, deren juristischer Status unsicher war, könnten von dem nationalsozialistischen Regime angetastet werden. Eine Verletzung der Rechts deutscher Bürger habe er sich nicht vorstellen können. - Katz, Autobiographie, S. $90 \mathrm{f}$.

30 YIVO, American Jewish Committec, Collection Waldmann, RG 347.1, Box 4, Folder 89, Cyrus Adler, Präsident, an Alfred Cohen, Präsident von B'nai B'rith, Cincinnati, 3. 2. 1933.

31 Bauer, Brother's Keeper. Kahn war überzeugt, daß selbst ausländische Juden infolge der antideutschen Interessen ihrer jeweiligen Regierungen in der einen oder anderen Form geschützt seien. 
In den ersten Jahren nach 1933 war das neue Regime stark auf die Konsolidierung seiner internationalen Position angewiesen. Immer wieder jedoch standen die auBenpolitischen Bemühungen des Reiches im Widerspruch zu der extrem gewalttätigen Politik, mit der innerhalb des Reiches die neue Ordnung durchgesetzt und konsolidiert werden sollte. Die Behandlung des Problems ausländischer Juden ist ein deutliches Beispiel für diese Diskrepanz. Um der antisemitischen Politik des neuen Regimes eine breite Unterstützung zu garantieren, instrumentalisierte man konsequent die osteuropäisch-jüdische Bevölkerung. Die nationalsozialistische Propaganda erinnerte ohne Unterlaß an die Problematik der Präsenz von ausländischen Juden in Deutschland. Dabei ging man von einem internationalen Konsens darüber aus, daß die zahlreichen Immigranten für die Notsituation in Deutschland verantwortlich seien ${ }^{32}$. Bei deutschen Regierungsstellen glaubte man, daß selbst innerhalb jüdischer Kreise in anderen Ländern Polemik und Angriffe gegen osteuropäische Juden auf ein gewisses Verständnis stoßen würden 33 . Doch das Auswärtige Amt war sich darüber hinaus sehr wohl bewußt, daß zwischen der Hetze gegen osteuropäische Juden, wie das Regime sie für innenpolitische Zwecke betrieb, und der „sachlichen, neutralen Form “ unterschieden werden müsse, in der diese Propaganda außerhalb der Reichsgrenzen eingesetzt werde ${ }^{34}$. Sieben Wochen nach der Machtübernahme der Nationalsozialisten schloß das Regime in die allgemeinen antijüdischen, diskriminierenden Gesetze auch die ausländischen Juden mit ein ${ }^{35}$. Zunächst ging es nur um die Verhinderung einer weiteren Zuwanderung von Juden aus dem Osten. Doch relativ schnell wandte sich die Diskussion dem Status der bereits in Deutschland lebenden osteuropäischen Juden zu. Ein Versuch, diese Juden sofort auszuweisen, konnte nicht in die Tat umgesetzt werden. Allerdings führten die Debatten zu einer Neudefinition des Status vieler Angehöriger dieser Gruppe in Deutschland. Auf einer Sitzung des Reichsministeriums des Inneren am 14. Juli 1933 wurde beschlossen, alle nach 1918 erfolgten Einbürgerungen von Ausländern zu überprüfen. Es sollte geprüft werden, ob diese Einbürgerungen mit den nationalen Interessen Deutschlands vereinbar seien, wie sie nach dem Regierungswechsel von 1933 neu definiert worden waren. Tausende von Personenakten in den Archiven der deutschen Länder dokumentieren, daß in den meisten Fällen osteuropäi-

32 Anweisungen des deutschen Auswärtigen Amtes an dic diplomatischen Auslandsvertretungen Deutschlands, wie die antijüdische Politik Deutschlands im Ausland darzustellen sei, liefen darauf hinaus, daß man sich in der Erläuterung auf den negativen Einfluß der osteuropäischen Juden auf das Leben in Deutschland zu konzentrieren habe. BAK, R 43II/600, Rundschreiben vom 30. 4. 1933. Ähnlich auch ein Gutachten verschiedener offizieller deutscher Stellen zum Erfolg dieser Propagandalinie: PAAA, R 99400, Deutsches Konsulat Saigon an das Auswärtige Amt, 14.9. 1933; BAP, 15.01 Reichsministerium des Inneren, 25673/28, Nachrichten des Geheimen Staatspolizeiamtes am 14. 11. 1933.

33 Ein deutscher Industrieller berichtete nach seiner Rückkehr aus England, daß „die intelligenten Juden Verständnis für die Ausschaltung der polnischen Juden haben“. - LBI-N.Y., Max Kreutzberger Collection, AR 7183, Box 19, Folder 2, Ludwig Krumm A.-G. an MinRat Willuhn, Reichskanzlei, Berlin, 17. 9. 1934.

34 So z. B. die Broschüre „Ist das Verlangen des deutschen Volkes nach Entjudung berechtigt?“, die ursprünglich für innenpolitsche Zwecke verfaßt, dann aber für ausreichend sachlich befunden wurde, um von den deutschen Auslandsvertretungen eingesetzt zu werden: PAAA, $\mathrm{R}$ 84333, Auswärtiges Amt an alle diplomatischen und konsularischen Auslandsvertretungen, 26.7. 1933.

35 Hilberg, Vernichtung, S. 38. 
schen Juden, die nach dem Ersten Weltkrieg die deutsche Staatsbürgerschaft erworben hatten, diese nun infolge der Überprüfung aberkannt wurde. In der erwähnten Sitzung äußerte Hitlex, daß im Unterschied zu den Reaktionen auf das Vorgehen gegen einheimische Juden die gegen ausländische Juden ergriffenen Maßnahmen auf allgemeines Verständnis stießen ${ }^{36}$.

Derartige Tendenzen schufen eine günstige Atmosphäre für Übergriffe gegen ausländische Juden. In den ersten Monaten des Jahres 1933 nahmen infolgedessen die Angriffe gegen Leib und Leben von Juden osteuropäischer Herkunft erheblich $\mathrm{zu}$, wie die zahlreichen Beschwerden der Betroffenen bei den ausländischen Konsulaten belegen ${ }^{37}$. Viele dieser Anschläge wurden von Privatpersonen ausgeführt: Passanten, Nachbarn und Geschäftskonkurrenten. Doch auch SS und SA initiierten Angriffe. In vielen Fällen wurden ausländische Juden von Maßnahmen betroffen, die eigentlich Juden insgesamt galten, wie z.B. den Boykottmaßnahmen am 1. April 1933. Es fehlten jedoch keineswegs Aktionen, die gezielt gegen polnische Juden gerichtet waren - vielleicht weil sie leichter als Juden identifiziert werden konnten. Die traditionelle äußere Erscheinung vieler polnischer Juden, die äußeren religiösen Merkmale (Bart oder Gebetsmäntel und Schaufäden) sowie die Tendenz, sich - anders als deutsche Juden, deren Religionspraxis sich in der Privatsphäre abspielte mit anderen Juden zu Gebet und Unterhaltung an öffentlichen Stätten zu versammeln, waren Faktoren, die die Aufmerksamkeit erregten und gezielte Angriffe erleichterten. In extremen Fällen wurden Juden auf der Straße oder in den Kellern der SA Bärte und Schläfenlocken abgeschnitten oder die Gebetsmäntel zerrissen ${ }^{38}$. Polnische Juden, die sich bei den polnischen Konsulaten beschwerten, gaben an, sie hätten auf ihre ausländische Staatsbürgerschaft hingewiesen, in der Hoffnung, dies werde sie vor Gewalt bewahren. Derartige Hinweise seien jedoch von den Tätern mit Spott aufgenommen worden, und in vielen Fällen hätten solche Äußerungen nur zu weiterer Brutalität geführt ${ }^{39}$. Die Polizei, die im Unterschied zu parteilichen Gruppierungen wie SS und SA unter normalen Umständen offiziell als „Hüterin des Gesetzes" und Repräsentantin des Staates fungiert hätte, war von Antisemitismus und feindseligen Vorurteilen osteuropäischen Juden gegenüber nicht frei und betrachtete polnische Juden keineswegs mit Wohlgefallen ${ }^{40}$. In vielen Fällen be-

36 BAK, R 43II/134, Auszug aus der Niederschrift über die Sitzung des Reichsministeriums, 14. Juli 1933.

37 Tausende derartiger Beschwerden finden sich in den Akten der polnischen Konsulate in Deutschland (heute im AAN in Warschau aufbewahrt) sowie in der Korrespondenz zwischen dem deutschen Ministerium für Auswärtige Angelegenheiten und den ausländischen Konsulaten und Botschaften im PAAA in Bonn.

38 AAN, Amb Rp w Berlinie, Akt Nr. 864, Dr. T. Brzezinski, Konsul der Republik Polen, an das Ministerium für Auswärtige Angelegenheiten in Dresden, 28.3. 1933; sowie im Falle Herrn Wiedens: AAN, Amb Rp w Berlinie, Akt Nr. 864, Konsul Dr. A. Kruczkiewicz an den Polizeipräsidenten, IV.1933.

39 Unter den zahlreichen Beschwerden in den Akten der polnischen Konsulate in Deutschland und dem AAN in Warschau finden sich unzählige Beispiele für derartige Vorfälle, so z. B.: AAN, Amb Rp w Berlinie, Akt Nr. 898, Beschwerden Abram Knop, Julius Kalinowski, Kalman Steiner-Ball; Akt Nr. 899, Beschwerden Karl Katzenell, Adolf Kessler.

40 So hieß es in dem Polizeibericht gegen den polnisch-jüdischen Händler Julius Lieber: „Lieber ist ein typischer Vertreter der ostjüdischen Rasse. Er ist einer jener Schädlinge, der durch Betrügereien und undurchsichtige Geldgeschäfte eine größere Anzahl deutscher Kaufleute und Kunden empfindlich schädigte." - AAN, Amb Rp w Berlinie, Akt. Nr. 902, Polizeidi- 
mühte sich die Polizei daher nicht, die vom Pöbel oder SS- und SA-Angehörigen angegriffenen Juden zu schützen ${ }^{41}$.

Wiederholte Vorfälle dieser Art führten zu Interventionen offizieller polnischer Stellen. Im wesentlichen bestanden die polnischen Konsulate auf ihrem legitimen Recht, in Deutschland lebende polnische Staatsbürger zu schützen. Deutsche Behauptungen, nur die Betroffenen selbst könnten Beschwerde gegen derartige Vorfälle einlegen, wurden von den polnischen Konsulaten zurückgewiesen ${ }^{42}$. Darüber hinaus weigerten sich die polnischen Vertretungen, das Argument deutscher Stellen zu akzeptieren, es handele sich um persönliche Angelegenheiten und keineswegs um Vorgänge im öffentlichen Interesse. Die polnischen Vertretungen betonten vielmehr den politischen Hintergrund der tätlichen Angriffe gegen Juden mit polnischer Staatsbürgerschaft und hoben ihren rassistischen Aspekt hervor ${ }^{43}$. In ihren Versuchen, die deutschen Behörden zum Schutz polnischer Staatsbürger zu veranlassen, wiesen dic polnischen Stellen auf den negativen Eindruck hin, den derartige Ereignisse in der polnischen Öffentlichkeit hinterließen ${ }^{44}$. Um die Bearbeitung der zahlreichen, in den ersten Monaten des Jahres 1933 eingehenden Beschwerden zu beschleunigen, versuchten die polnischen Konsulate diese Beschwerden direkt an die lokalen Behörden weiterzuleiten und so das übliche Verfahren, jede einzelne Beschwerde dem Außenministerium zur zentralen Bearbeitung vorzulegen, zu umgehen ${ }^{45}$.

Sich bei den polnischen diplomatischen Vertretungen zu beschweren, war für die Betroffenen ein Weg, Druck auf die verschiedenen Instanzen des NS-Regimes auszuüben, und bisweilen konnte so der den polnischen Juden zugefügte Schaden tatsächlich begrenzt werden. Dennoch standen die Beschwerdeführer vor zahlreichen Schwierigkeiten. Die NSDAP versuchte, mit massivem Druck und bisweilen mit Gewalt, Juden von Beschwerden bei den Konsulaten abzuhalten ${ }^{46}$. Nach Einschätzung des polnischen Konsuls in München wurden die meisten Betroffenen entsprechend drangsaliert ${ }^{47}$. Derartiger Terror war dann auch so erfolgreich, daß selbst viele jüdische Gemeinden und Organisationen ihre Beschwerden zurückzogen und in einigen Fällen sogar behaupteten, ihre Lebensumstände seien unter der NS-Herr-

rektion Kaiserslautern an das Präsidium der Regierung der Pfalz Speyer/Rhein, 4. 5. 1933; StA Leipzig, PP-V 4406, 4407, Polizeipräsidium Leipzig, Abt. IV, 2. 12. 1934.

41 Eines von vielen Beispielen: AAN, Amb Rp w Berlinie, Akt Nr. 906, Der polnische Vizekonsul Rosmanski an den Regierungspräsidenten in Münster, 13. 9. 1933.

42 AAN, Amb Rp w Berlinie, Akt Nr. 910, p. 153, Konsul der Republik Polen an den Regierungspräsidenten in Düsseldorf, 24.3.1933.

43 AAN, Amb Rp w Berlinie, Akt Nr. 893, M. Czudowski, Konsul der Republik Polen in Leipzig, an den Oberstaatsanwalt bei dem Landesgerichte in Leipzig, 31. 1. 1936.

${ }^{4}$ AAN, Amb Rp w Berlinie, Akt Nr. 864, Der Leiter des Generalkonsulats Bohdan Samborski an den Oberpräsidenten der Provinz Oberschlesien in Oppeln, 7. 4. 1933.

45 Vgl. AAN, Amb Rp w Berlinie, Akt Nr. 864, Dr. T. Brzezinski, Konsul der Republik Polen, an das Ministerium für Auswärtige Angelegenheiten in Dresden, 5. 4. 1933.

46 PAAA, R 100209, Aide-memoire der Polnischen Gesandschaft in Berlin, 2. 5. 1933. - Mozes Weinreb zog seine Beschwerde beim Konsulat mit dem diskreten Hinweis zurück, man hätte ihm entsprechende Drohungen zukommen lassen: AAN, Amb Rp w Berlinie, Akt Nr. 867, p. 299, Mozes Weinreb an das Polnische Konsulat in Frankfurt a.M., 2. 6. 1933.

47 AAN, Amb Rp w Berlinie, Akt. Nr. 893, Dr. Adam Lisiewicz an die bayerische Staatskanzlei am 14. 4. 1933. 
schaft unverändert geblieben ${ }^{48}$. Die polnischen Konsulate behandelten die Beschwerdeanträge der in Deutschland lebenden polnischen Juden im wesentlichen sachlich und korrekt. Dennoch stießen die Antragsteller auch hier auf manche Verzögerung. So wurde die Korrespondenz zwischen den Konsulaten und den Beschwerdeführern ausschließlich in polnischer Sprache geführt, ein Umstand, der für diejenigen polnische Juden, die nur Jiddisch sprachen, eine große Schwierigkeit darstellte ${ }^{49}$. Darüber hinaus legten die deutschen Behörden den diplomatischen Vertretungen etliche Schwierigkeiten in den Weg. Oft wurden internationale Abkommen über den Umgang mit Bürgern befreundeter Staaten nicht beachtet: So versuchten deutsche Behörden den Besuch polnischer Konsularvertreter bei verhafteten polnischen Juden zu verhindern ${ }^{50}$.

Die zahlreichen Beschwerden ausländischer diplomatischer Vertretungen über Verletzungen der Rechte ihrer jüdischen Staatsangehörigen in Deutschland veranlaßten die deutschen Behörden zu einer grundsätzlichen Erörterung der Politik gegenüber Ausländern, insbesondere aber ausländischen Juden in Deutschland. Die deutsche Politik war unter Druck geraten: Die Angriffe gegen Staatsangehörige fremder Staaten erzeugten bei der Weltöffentlichkeit ein negatives Deutschlandbild. Schon Anfang April 1933 hatte der deutsche Außenminister Konstantin Freiherr von Neurath in einem Brief an Reichsinnenminister Wilhelm Frick gewarnt, man müsse derartige Vorfälle und Angriffe auf ausländische Staatsangehörige in Zukunft unbedingt verhindern, denn sie schädigten den Ruf der Regierung und des deutschen Volkes ${ }^{51}$. Darüber hinaus war Deutschland natürlich an internationale Abkommen, insbesondere an Handelsabkommen, gebunden, deren Verletzung die Lage deutscher Minderheiten in anderen Ländern hätte beeinträchtigen können. Auch wenn die Zahl der im Ausland lebenden Deutschen letztlich niedriger sei als die Zahl der Bürger jener Staaten in Deutschland, so die Argumentation im Auswärtigen Amt, sollte Deutschland doch ein größeres Interesse am Schutz der Deutschen im Ausland haben als an einer Verletzung der Ausländer in Deutschland 52.

Eine zusätzliche entscheidende Frage betraf die Behandlung ausländischer Juden im Vergleich zur Behandlung deutscher Juden. Eine uneingeschränkte Achtung der Rechte von Juden mit ausländischer Staatsbürgerschaft hätte ihnen eine den deutschen Juden gegenüber bevorzugte Stellung verliehen. So begnügte sich die Propaganda zunächst nicht mit der Verunglimpfung osteuropäischer Juden, sondern versuchte, die verhaßten ausländischen Juden mit den von Teilen der Gesellschaft durchaus als „ehrenwert" betrachteten einheimischen Juden zu assoziieren und so

48 So z. B. die Gemeinde Waldenburg in Schlesien: AAN, Amb Rp w Berlinie, Akt. Nr. 864, die Synagogengemeinde Waldenburg in Schlesien an die polnische Botschaft, Berlin, 31. 3. 1933, oder: AAN, Amb Rp w Berlinie, Akt Nr. 864, das Komitee der in München lebenden Juden polnischer Staatsangehörigkeit an das polnische Generalkonsulat München, 31.3. 1933.

49 In einem Brief eines polnischen Konsularangestellten in Leipzig heißt es, das polnische Konsulat würde nur ausnahmsweise auf Deutsch antworten. - AAN, Amb Rp w Berlinie, Akt Nr. 907, J. Witkowski, 22. 12. 1933.

50 AAN, Amb Rp w Berlinie, Akt Nr. 908, Ministerium für Auswärtige Angelegenheiten in Sachsen an das Konsulat der Republik Polen in Leipzig, 10. 4. 1933.

51 BAK, R 43II/134, Von Neurath an Frick, 6. 4. 1933.

52 PAAA, R 100211, Ressortbesprechung im Auswärtigen Amt über die Behandlung von Ausländern, insbesondere ausländischen Juden, 25. 8. 1933. 
die antisemitische Politik insgesamt zu rechtfertigen ${ }^{53}$. Trotzdem blieben osteuropäische Juden allein schon infolge ihrer „Andersartigkeit“ zentrales Ziel antisemitischer Propaganda. In einem Schreiben des Auswärtigen Amtes an das preußische Innenministerium wurde wie selbstverständlich davon ausgegangen, „daß es durchaus unerwünscht wäre, wenn ausländischen Juden in irgendeiner Hinsicht Rechte eingeräumt werden müßten, die den inländischen Juden nicht gewährt werden“. Der einzige Gesichtspunkt, bei dem von diesem Grundsatz „abgewichen werden müßte“, sei „das Entgegenstehen völkerrechtlicher Bindungen“54.

Um den Spielraum abzustecken, der dem NS-Regime bei den Maßnahmen gegen ausländische Juden zur Verfügung stand, kam es am 25. August 1933 zu einer koordinierenden Ressortbesprechung von Vertretern des deutschen Auswärtigen Amtes, des Reichsinnen- und des Reichsjustizministeriums ${ }^{55}$. Eine derartige Besprechung war infolge der zunehmenden Entschädigungsforderungen, die von ausländischen diplomatischen Vertretungen in Deutschland wegen der permanenten Verletzungen von Rechten ihrer Staatsangehörigen gestellt wurden, notwendig geworden.

Um dem Widerspruch zwischen dem Unwillen der deutschen Behörden, ausländische Opfer der antisemitischen Politik zu entschädigen, und der Verpflichtung Deutschlands zur Einhaltung internationaler Verträge und internationalen Rechts $\mathrm{zu}$ entgehen, sollten Richtlinien für die Behandlung von ausländischen Juden in Deutschland aufgestellt werden. Die Teilnehmer der erwähnten Ressortbesprechung waren sich einig, daß zunächst Forderungen gegen Deutschland vor internationalen Körperschaften verhindert werden müßten. Weiterhin verlangten sie, die Bearbeitung der Entschädigungsanträge innerhalb Deutschlands zu vereinheitlichen und die Wiederholung von unerwünschten Tätlichkeiten und Ereignissen einzuschränken. Die beschlossenen Richtlinien sahen vor, daß in Fällen, in denen ausländische Juden ihren Arbeitsplatz verloren hatten, der private Charakter dieser Entlassungen betont sowie die Tatsache hervorgehoben werden sollte, die Entlassung eines osteuropäischen Juden sei keineswegs eine Diskriminierungsmaßnahme gegen ausländische Juden, weil eine entsprechende Politik auch gegenüber deutschen Juden betrieben werde. Außerdem wurden die Behörden angewiesen, die Antragsteller auf eine infolge sorgfältiger Prüfung jedes einzelnen Antrags entstehende lange Wartezeit aufmerksam zu machen und am Ende der Bearbeitung Entschädigungsansprüche zurückzuweisen. Ein positiver Entscheid über Entschädigungen in Fällen, in denen es keinen anderen Ausweg gebe, könne nur von den zentralen Spitzenbehörden getroffen werden. Allgemein, so das Sitzungsprotokoll, sollten die Ämter grundsätzlich anerkennen, daß verschiedene Vorfälle nicht mit dem Gesetz vereinbar seien. Stets sollte jedoch darauf hingewiesen werden, daß dies auf den zur Prüfung vorgelegten Einzelfall nun allerdings gerade nicht zutreffe.

Trotz der Versuche, sich auf eine einheitliche Linie zu einigen, blieb es bei verworrenen, allgemeinen Hinweisen, die in der Realität erneut zu Widersprüchen führten. Beharrlich erging von verschiedenen Stellen wie der Polizei oder den Lokalbehörden die Aufforderung, keine ausländischen Staatsangehörigen anzugreifen.

53 BAK, R 43II/600, Auswärtiges Amt, 30. 4. 1933, wie in Anmerkung 32.

54 PAAA, R 100211, Auswärtiges Amt an den preußischen Minister des Innern, 31. 3. 1934.

55 PAAA, R 100211, Ressortbesprechung im Auswärtigen Amt über die Behandlung von Ausländern, insbesondere ausländischen Juden, 25. 8. 1933. 
Der Oberpräsident der Provinz Ostpreußen z.B. meinte, daß lokale SA-Mitglieder einen polnischen Juden nicht angegriffen hätten, wenn ihnen dessen polnische Staatsbürgerschaft bekannt gewesen wäre ${ }^{56}$. Die Polizei in Recklinghausen ging sogar noch weiter und verkündete, daß derjenige, der eine "Sonderaktion“ gegen ausländische Bürger durchführe, ein Feind des nationalsozialistischen Staates sei und mit einer besonders schweren Strafe zu rechnen habe ${ }^{57}$. Gleichzeitig setzten verschiedene Regierungsstellen ihre gezielten Angriffe gegen ausländische Juden oder Angriffe im Rahmen der allgemeinen Maßnahmen gegen Juden überhaupt fort. Die Beamten auf lokaler Ebene konnten nur schwer akzeptieren, daß ausländischen Juden mehr Rechte zugestanden werden sollten als einheimischen. Ein polnischer Jude auf dem Markt im württembergischen Schramberg wurde daher aufgefordert, seinen Marktstand zu schließen und den Ort zu verlassen, während deutsch-jüdische Händler auf dem Markt verbleiben durften ${ }^{58}$. In der Pfalz wurde der Antrag eines polnischen Juden auf Wohlfahrtsmarken mit dem Argument abgelehnt, die Gewährung dieser Wohlfahrtsunterstützung würde ihm einen privilegierten Status gegenüber einheimischen Juden einräumen und einen Präzedenzfall für weitere derartige Forderungen schaffen ${ }^{59}$. Auch die Öffentlichkeit in Deutschland wollte nur schwer einsehen, daß gerade die ungeliebten osteuropäischen Juden einen besonderen gesetzlichen Schutz erhielten. Nach dem Verständnis der Straße hätten sich antisemitische Aktionen und Maßnahmen gerade gegen ausländische, nicht aber gegen einheimische Juden richten müssen!

Die Widersprüche lösten sich jedoch im Laufe der dreißiger Jahre auf. Die Konsolidierung des NS-Regimes in Deutschland und die politische Ausschaltung der SA 1934 bereiteten den „spontanen“ Ausbrüchen antisemitischer Gewalt ein Ende und führten zur Herausbildung einer konzentrierten und kontrollierten antijüdischen Politik. Gleichzeitig konnte das nationalsozialistische Deutschland seine Position auf internationaler Ebene sichern. Es fühlte sich fortan unabhängiger von der öffentlichen Meinung in anderen Staaten. Auch im Hinblick auf die Erfüllung internationaler Abkommen konnte das Regime sich ungebundener verhalten. Der Nichtangriffspakt zwischen Polen und Deutschland von 1934 klammerte das Problem der Minderheiten aus und erleichterte dem NS-Regime die Entwicklung normaler Beziehungen zum benachbarten Polen, wobei allerdings die in Deutschland lebende polnische Minderheit ebenso wie polnische Juden in Polen weiterhin Schikanen ausgesetzt blieben ${ }^{60}$. Die Bearbeitung der Beschwerden polnischer Juden er-

56 AAN, Amb Rp w Berlinie, Akt Nr. 899, Der Oberpräsident der Provinz Ostpreußen an das polnische Konsulat, 24. 6. 1933.

57 AAN, Amb Rp w Berlinie, Akt Nr. 870, Recklinghauser Volkszeitung, 27. 8. 1935.

58 AAN, Amb Rp w Berlinie, Akt Nr. 901, der Attache W. Mieczystawski an das Württembergische Innenministerium in Stuttgart, 1. 8. 1933.

59 AAN, Amb Rp w Berlinie, Akt Nr. 900, Regierung der Pfalz, Kammer des Innern, an das polnische Generalkonsulat in Frankfurt a. Main, Speyer, 23. 2. 1934.

60 Die atmosphärische Bedeutung dieses Abkommens mag folgender Vorfall veranschaulichen: In Warschau erhielt der jüdische Händler Halberstadt einen Brief von einer deutschen Firma. Halberstadt schickte den Brief zurück, wie er gekommen war, und fügte auf der Rückseite beleidigende Äußerungen gegen den „Führer" hinzu. Gegen Halberstadt wurde von polnischer Seite ein Verfahren wegen Verunglimpfung einer führenden Persönlichkeit eines fremden Staates eingeleitet. Er erhielt eine Haftstrafe von acht Monaten. StA Dresden, 
folgte fortan nur auf geheimen diplomatischen Wegen 61 . Wie wir sehen werden, kam es im Laufe der dreißiger Jahre und insbesondere nach dem Tode des polnischen Präsidenten Pilsudski 1935 zu einer zunehmenden Verschlechterung der Situation von Juden in Polen selbst. Der wachsende Antisemitismus im eigenen Lande schwächte die Position der polnischen Konsulate bei der Betreuung der polnischen Juden in Deutschland. Im polnischen Außenministerium ging man 1936 davon aus, daß Juden innerhalb weniger Jahre aus der deutschen Wirtschaft und Gesellschaft ohnehin völlig verdrängt sein würden. Polnische Juden schützen zu können, war daher für die polnischen Konsulate eine zweitrangige Frage. Nicht auf ihren Schutz sollten sich die Konsulate konzentrieren, sondern auf die Verhinderung einer Migration mittelloser polnischer Juden von Deutschland nach Polen ${ }^{62}$. In der zweiten Hälfte der dreißiger Jahre kam es tatsächlich zu einem Rückgang der Eingaben bei den polnischen Konsulaten, und zwar in erster Linie wohl infolge der Einschränkungen „spontaner" Aktionen gegen Juden, sicherlich aber auch infolge des allgemein sich verbreitenden Gefühls, die Konsulate hätten immer weniger Möglichkeiten, den Beschwerdeführern wirklich Hilfe zu leisten. Darüber hinaus nahm die Furcht auf polnischer Seite vor einer möglichen Migration mittelloser polnischer Juden aus Deutschland nach Polen zu. Der polnische Sejm schuf im März 1938 die gesetzliche Grundlage für die Ausbürgerung in Deutschland lebender polnischer Juden. Als Reaktion darauf wies Deutschland im Oktober 1938 die Mehrheit der in deutschem Gebiet lebenden polnischen Juden nach Polen aus und ließ so die Befürchtungen der polnischen Regierung Wirklichkeit werden. Diese Ereignisse werden im weiteren Verlauf unserer Darstellung ausführlicher erörtert werden.

\section{Deutsche Juden am Scheideweg: Zwischen Religion und Rasse}

Die Einstellung den Einwanderern aus Osteuropa gegenüber war von hoher Signifikanz für die verschiedenen politischen Lager des deutschen Judentums. Die Zionistische Vereinigung für Deutschland identifizierte sich seit ihrer Gründung 1897 mit den osteuropäischen Juden und setzte sich in den jüdischen Gemeinden und gegenüber dem deutschen Staat für deren Interessen ein. Diese Haltung wurde durch einen Generationswechsel in der Führungspitze der Zionistischen Vereinigung noch verstärkt ${ }^{63}$. Demgegenüber verstand sich der 1893 gegründete Central Verein deutscher Staatsbürger jüdischen Glaubens (künftig: Central Verein) allein als Repräsentant der deutschen Juden, also der Juden mit deutscher Staatsbürgerschaft, und fühlte sich für die Belange ausländischer Juden in Deutschland nicht zuständig. Im Laufe der zwanziger Jahre, auch hier vor allem infolge des Generationswechsels in der Führung des Central Vereins Ende der zwanziger Jahre, änderte sich die Haltung des Vereins gegenüber der Zionistischen Bewegung und zur Besiedlung Palä-

Zeitungsausschnittsammlung Nr.583, Nachrichtenstelle der Staatskanzlei, Chemnitzer Tageblatt, 26. 9. 1935.

61 Tomaszewski, Polish Diplomats, S. 191.

62 Bericht Stefan Odrowaza-Wysocki, Konsularabteilung des polnischen Auswärtigen Amtes, in: Jonca, Niemiecko Polski, S. 106.

63 Lavski, German Zionism, S. $25 \mathrm{ff}$. 
stinas. Diese Veränderungen strahlten auch auf die Einstellung des Vereins zu den osteuropäischen Juden aus und verringerte die vorhandene Distanz. Dennoch konnte der Central Verein sein in Deutschland bekanntes Image, er lehne osteuropäische Juden im Prinzip ab, nicht ablegen.

Die Konfrontation zwischen Zionistischer Vereinigung und Central Verein und die Ablehnung der osteuropäischen Juden durch den Central Verein machte sich die nationalsozialistischen Propaganda zu Nutzen. Die Gestapo hatte die Affinität zwischen osteuropäischen Juden und Zionistischer Vereinigung in Deutschland sowie die demonstrative Distanz der Mitglieder des Central Vereins zu osteuropäischen Juden aufmerksam verzeichnet ${ }^{64}$. Die Ablehnung osteuropäischer Juden durch deutsche Juden kam den Antisemiten sehr gelegen. Die deutsche Gesellschaft, so wurde argumentiert, sei nicht verpflichtet, osteuropäische Juden mit Sympathie zu betrachten, wenn sie selbst unter den Angehörigen ihres eigenen Volkes keinerlei Wohlwollen genössen. Außerdem wurde der Mangel an innerjüdischer Solidarität deutlich. Dies wiederum konnte als allgemeine jüdische Charakterschwäche ausgelegt und in der Propaganda gegen Juden instrumentalisiert werden. Es verwundert daher keineswegs, wenn die NS-Propaganda Worte Albert Einsteins von 1930 zitierte, in denen er gegen die Ablehnung der osteuropäischen Juden durch den Central Verein polemisierte ${ }^{65}$ :

„Wenn ich die Redensart höre ,Deutscher Staatsbürger jüdischen Glaubens', so muß ich lachen. Diese Staatsbürger wollen erstens nichts mit meinen armen ostjüdischen Brüdern zu tun haben; zweitens nicht Söhne meines (des jüdischen) Volkes sein, sondern nur Mitglieder der jüdischen Kulturgemeinschaft. Ist das ehrenhaft? Kann ein Nichtjude Leute, die sich so verstehen, achten? Ich bin kein deutscher Staatsbürger. Ich bin Jude und froh, dem jüdischen Volke anzugehören."

Nach 1933 verringerten sich in der Presse des Central Vereins allmählich die Anzeichen der Distanzierung gegenüber osteuropäischen Juden, wie Einstein sie beschrieben hatte. Auch wenn im Central Verein bisweilen Vorwürfe gegen Juden osteuropäischer Herkunft erhoben wurden, so klang dabei doch häufig ein versöhnlicher und in gewissem Maße auch apologetischer Ton an ${ }^{66}$. Führende Kräfte des Central Vereins wählten ihre Worte mit großem Bedacht, wenn sie sich zu den negativen Auswirkungen der Masseneinwanderung äußerten. Ludwig Holländer, der Vorsitzende des Central Vereins, meinte Ende 1933, dem negativen Image der osteuropäischen Juden liege der Umstand zugrunde, daß man sie mit der Masseneinwanderung identifiziere ${ }^{67}$. „Die Brotlosen unter uns," schrieb Holländer, "gut deutschgesinnt, die sich eine neue Grundlage ihres wirtschaftlichen Daseins suchen mußten, werden in den Ländern des Westens vielfach als Ostjuden bezeichnet. Man suche sich darüber klar zu werden, daß es überall in der Welt eine Menge von aus dem Osten stammenden jüdischen Menschen gibt, die sich an Sittlichkeit und Ar-

64 BAP, 15.01, Reichsministerium des Innern, Nr. 26060, Staatspolizeistelle Stettin an das Geheime Staatspolizeiamt, 5. 2. 1934; Nr. 26059, Staatspolizeistelle für den Regierungsbezirk Arnsberg. Berichterstatter Reg. Ass. Dr. Blume: Das jüdische Problem in seiner neuesten Entwicklung, 5. 3.1934.

65 Einstein, Zionism, S. 23 f., zitiert in: Rose, Juden richten sich, S. 30 f.; sowie in: Frecks, Das rassische Erwachen, S. 24.

66 C.V.Z., Zur Braunschweiger Tagung des Handelsstandes, Nr. 45, 23. 11. 1933.

67 C.V.Z., Ludwig Holländer, Grundbegriffe der jüdischen Gegenwart, Nr. 50, 29. 12. 1933. 
beitsamkeit mit jedem, aber auch mit jedem messen können. Aber bei großen Wanderungen werden sehr oft auch faule Elemente abgestoßen."

In der ersten Zeit nach Hitlers Machtübernahme verstand sich ein großer Teil der jüdischen Gesellschaft in Deutschland weiterhin als Teil des deutschen Staates, und zwar weit über eine bloß durch die Staatsbürgerschaft gewährte Zugehörigkeit hinausgehend im Sinne einer deutsch-jüdischen Schicksalsgemeinschaft. Im Unterschied zu den Zionisten, die von der Existenz einer separaten jüdischen Nation ausgingen und für die die Bindung an die jüdische Nation stärker war als die staatsbürgerliche Verpflichtung, verstanden liberale Juden und ihre verschiedenen Organisationen die Zugehörigkeit zu einer jüdischen Nation als ausschließliche Angelegenheit osteuropäischer Juden ${ }^{68}$. Die kompromißlose Loyalität, die jüdisch-liberale Kreise der deutschen Gesellschaft gegenüber an den Tag legten, war eine ergiebige Quelle zionistischer Kritik. Mit bitterer Ironie bedauerte ein zionistischer Aktivist aus Mainz Ende 1933, daß „gewisse ,westeuropäische' Kreise auch heute noch nichts gelernt haben und bewußt allen Veranstaltungen fernbleiben, die irgendwie mit Zionismus zusammenhängen, und [...] nur darauf warteten, bis in der NSDAP eine Abteilung für ,germanische Nichtarier" gegründet wird"69.

Die Mitglieder des Central Vereins, der die zahlenmäßig stärkste politische jüdische Organisation jener Jahre war, begannen keineswegs über Nacht, sich für den Zionismus zu interessieren. Zwar hatte sich der Central Verein seit seiner Gründung dem Kampf gegen den Antisemitismus verschrieben und diesen Kampf auch infolge der Zunahme antisemitischer Tendenzen in Deutschland Ende der zwanziger Jahre deutlich verstärkt. Die Mitglieder des Central Vereins leugneten ihre jüdische Identität nicht, wollten diese Identität jedoch als gleichwertig und gleichrangig mit ihrer deutschen Identität verstanden wissen. Nur die rechte Peripherie der jüdischen Bevölkerung in Deutschland, allen voran der Verband Nationaldeutscher Juden, betonte auch nach der politischen Wende von 1933 weiterhin ihre absolute und unerschütterliche Bindung an den deutschen Staat. Die Ursachen für die Entstehung des Verbandes Nationaldeutscher Juden um Max Naumann inncrhalb des Central Vereins und seiner Abspaltung im Jahr 1920 lagen in seinem kompromißlosen Kampf gegen die jüdische Einwanderung aus Osteuropa ${ }^{70}$. Die Hochburg der Naumann-Gruppe war Berlin, wo sie bei den Gemeindewahlen 1930 knapp 2\% aller abgegebenen Stimmen erhielt.

Auch 1933 setzte sie ihre hartnäckigen Kampagnen gegen ausländische Juden in Deutschland fort. Naumann forderte eine strikte Unterscheidung zwischen „Deutschjuden“ und „Fremdjuden“. Nach seiner Definition traf der Begriff „Deutschjuden“ ausschließlich auf die Mitglieder seiner Organisation zu, während andere Juden in Deutschland, also osteuropäische Juden, Zionisten und auch liberale Juden, unter die Kategorie der „Fremdjuden“ fielen ${ }^{71}$. Entscheidend für diese Zuordnung, so Naumann, sei die Frage der Solidarität. Naumann griff die Massen-

68 C.V.Z., Karl Löwenstein, Ordnung und Einordnung, Nr. 2, 11. 1. 1934. - Weiss, Wir Westjuden.

69 CZA, A 142/57/2, Julius Schottländer an Alfred Klee, 28. 11. 1933.

70 Zur Naumann-Gruppe siehe: Rheins, Verband nationaldeutscher Juden; Niewyk, Weimar Germany, S. $165 \mathrm{ff}$.

71 Der Nationaldeutsche Jude, Max Naumann, Der einzige Weg: die Ungleichschaltung!, 12. Jg., Nr. 4; Max Naumann, Deutschjuden und Fremdjuden, 12. Jg., Nr. 5, Dezember 1933. 
einwanderung an und meinte, „für die Juden, die aus dem Osten kamen, bestand die Besonderheit, daß inländische Juden ihnen behilflich waren, ihnen Schutz gewährten, ihre Sünden gegen das deutsche Wesen vertuschten und beschönigten und bei jeder Gelegenheit ibre Solidarität mit den ,Brüdern aus dem Osten" hervorhoben“. Wer jüdische Solidarität in irgendeiner Form zeige, sagte Naumann, sei ein „Fremdjude“. Ein „Deutschjude“ dagegen war Naumanns Definition zufolge derjenige, dessen Loyalität allein deutsch sei und der keinerlei Überlegungen anstelle, die den deutschen Interessen fremd seien ${ }^{72}$. Aus diesen Gründen lehnte er die Reichsvertretung der deutschen Juden, die als repräsentative Körperschaft des deutschen Judentums im September 1933 gegründet worden war, schlankweg ab. In einem offenen Brief im Oktober 1933 bezeichnete Naumann Leo Baeck, den Vorsitzenden der Reichsvertretung, und andere führende Persönlichkeit der deutschen Juden als Zionisten. Die Gründung der Reichsvertretung aber, so Naumann, zeige, daß „das Fremdjudentum endlich die Maske (hat) fallen lassen"73.

Naumann scheute kein Mittel, sich dem neuen Regime in Deutschland anzubiedern. Im März 1933 wandte er sich an Reichspräsident Paul von Hindenburg mit der Klage, ausländische Juden würden gegenüber deutschen Juden, die an der Front gedient hätten, bevorzugt behandelt ${ }^{74}$ :

„Als Frontsoldat werde ich stündlich mit Zuschriften und telefonischen sowie persönlichen Anfragen bestürmt, in denen zum Ausdruck kommt, daß gerade die deutschen Frontsoldaten jüdischer Abstammung es unbegreiflich und ungeheuerlich finden, wenn sie, die 12000 Tote für Deutschlands Ehre auf den Schlachtfeldern gelassen haben und von denen ein großer Teil als Schwerkriegsbeschädigte in das Vaterland zurückgekehrt ist, jetzt in diesem selben Vaterlande nicht nur als Bürger zweiter Klasse, sondern geradezu als lästige Ausländer behandelt werden sollen, während die wirklich lästigen Ausländer, gegen die wir nationaldeutschen Juden seit vielen Jahren in schärfstem Kampfe gestanden haben, unbehelligt umhergehen dürfen, weil über sie das Ausland seine schützende Hand hält, dasselbe Ausland, auf dessen Greulhetze sich diejenigen Herren, von denen der Boykott in Aussicht genommen wird, stützen."

Zwar wandten sich auch andere jüdische Organisationen in der Hoffnung an Hindenburg, ihren Status unter dem neuen Regime zu sichern. Der Reichsbund jüdischer Frontsoldaten betonte z. B. die Rechtsansprüche jüdischer Veteranen, ließ sich aber auf keinen direkten Vergleich zwischen ihnen und den Einwanderern ein ${ }^{75}$. Naumanns Vorwürfe gegen den bevorzugten Status ausländischer Juden stellten einen außergewöhnlichen Schritt dar, der geradezu den Charakter einer Denunziation hatte. Im gleichen Geiste wandte sich Naumann im April und Mai 1933 mit der Bitte an die Reichskanzlei, die Gleichberechtigung deutscher Juden anzuerkennen, diese Rechte den Zionisten und aus Osteuropa eingewanderten Juden jedoch abzusprechen ${ }^{76}$. Naumann trat für eine absolute Trennung zwischen „Deutschjuden“ gemäß seiner Definition - und den übrigen, in der Reichsvertretung organisierten Juden ein. Unter dem Motto „Ungleichschaltung!“ forderte er für seine Organisation und jene deutschen Juden, die seinen Weg für richtig hielten und sich ihm an-

72 So nach einem Interview, das Naumann 1933 dem niederländischen Rundfunk gab; SoA, 721/1/1993, Ein nationaldeutscher Jude am Wort.

73 RV, Deutschjuden! Erklärung des Verbandes nationaldeutscher Juden, Oktober 1933.

74 BAK, R 43II/600, Naumann an Hindenburg, 31.3. 1933.

75 BAK, R 43II/600, Reichsbund jüdischer Frontsoldaten an Hitler, 4. 4. 1933.

76 C.V.Z., 7. 9. 1933. 
schlössen, eine Sonderstellung gegenüber anderen Juden, denen er den Status von Ausländern zugewiesen wissen wollte ${ }^{77}$. In der Hoffnung auf Anerkennung durch das NS-Regime suchte er Kontakt zu Regierungsstellen ${ }^{78}$. So lud er einen Staatssekretär zu einem Vortrag mit dem bezeichnenden Titel „Deutsche Juden und internationale Juden" ein 79 .

Der Verband Nationaldeutscher Juden war eine Splittergruppe des Central Vereins. Die Beziehungen zwischen beiden Organisationen waren daher von Anfang an gespannt. Zielgruppe beider Organisationen war die liberal-jüdische Wählerschaft. Jedoch hatten sie völlig konträre Vorstellungen vom Abwehrkampf gegen den Antisemitismus, was natürlich für eine Fülle von Streitpunkten sorgte. Die große Aufmerksamkeit, die Naumanns Gruppe bei den Mitgliedern des Central Vereins erhielt, war angesichts des erheblichen Größenunterschieds beider Organisationen erstaunlich: Der Central Verein war die größte Körperschaft des deutschen Judentums, während Naumanns Organisation letztlich nur eine Randgruppe repräsentierte. Möglicherweise wurzelte die Aufmerksamkeit, die Naumanns Gruppe erhielt, in dessen ursprünglicher Absicht, die „Zwischenschichtler" auf seine Seite zu ziehen. Dadurch brachte er den Central Verein in eine Abwehrstellung ${ }^{80}$. Naumann stellte aufgrund seines Klassifikationsschemas von „Deutschjuden“ und „Fremdjuden" den Central Verein, die Zionistische Vereinigung und die osteuropäischen Juden als deutschfeindliche Gruppierungen in eine Reihe. Entsprechende Argumente, die auf den Versammlungen des Verbandes vorgetragen wurden, hatten den Charakter von Verleumdungskampagnen ${ }^{81}$, so daß sich der Central Verein zur Verteidigung gezwungen sah.

Die Auseinandersetzungen zwischen dem Central Verein und der NaumannGruppe - so peripher diese auch gewesen sein mag - waren Ausdruck für die Suche nach einem neuen Selbstverständnis des deutschen Judentums angesichts der Ereignisse ab 1933. Die wesentlichen Streitpunkte zwischen beiden Gruppen wurden in einer Debatte deutlich, die durch eine Versammlung der Naumann-Gruppe in Hanau ausgelöst wurde. Im Zentrum der Konfrontation stand das dort von Otto Mautner gehaltene Referat zu der Frage, wie sich Juden im neuen Staate zu verhalten hätten. Dabei schrieb er in einem historischen Überblick den osteuropäischen Juden eine negative Rolle bei der Gestaltung der Beziehungen zwischen Juden und

77 Naumann, Der einzige Weg: die Ungleichschaltung! - Der Begriff „Ungleichschaltung“ ist natürlich ein Wortspiel mit dem Begriff der Gleichschaltung, mit dem die Schritte zur Einschränkung der Opposition gegen das nationalsozialistische Regime bezeichnet wurden, während Naumann sich an die Regierungsstellen mit der Forderung wandte, die Mitglieder seiner Organisation von anderen Juden in Deutschland zu unterscheiden, nicht um für alle einen gleichen Status zu erwirken.

78 YVA, JM/2866, Naumann an den Herrn Reichsminister Frhr. v. Neurath, 13. 10. 1934.

79 YVA, JM/2866, Verband Nationaldeutscher Juden (Naumann) an den Staatssekretär, 19. 10. 1934.

80 Niewyk, Weimar Germany, S. 166, 168.

81 So z. B. in einer Rede in Frankfurt, in der die Mitglieder des Central Vereins beschuldigt wurden, zusammen mit den Zionisten und den Weimarer Regierungsbeamten Bardt und Goslar die Immigration von Juden aus Osteuropa nach Deutschland gefördert und damit das deutsche Nationalkapital gefährdert zu haben. SoA, 721/1/1993, Bericht über eine Versammlung des Verbandes Nationaldeutscher Juden in Frankfurt a.M., 4. 12. 1933. Ähnliche Äußerungen fielen in Hamburg: SoA, 721/1/1993, C.V. Hamburg an C.V. Berlin, 3. 10. 1933. 
Deutschen $\mathrm{zu}^{82}$. Jahrhundertelang seien Juden in Deutschland in das deutsche Volk integriert gewesen - im Hinblick auf ihre Lebensweise und ihr Zugehörigkeitsgefühl. Den Begriff „Alljudentum“ hätten erst die Juden aus Osteuropa verbreitet. Außerdem habe die Masseneinwanderung aus Osteuropa und die Beteiligung von osteuropäischen Juden an der Revolution in Deutschland 1918 die korrekten Beziehungen zwischen Juden und Deutschen negativ beeinflußt. Mautner stritt die Existenz eines allgemeinen innerjüdischen Zusammengehörigkeitsgefühls in all seinen Formen ab und wandte sich gegen die jüdische Boykottbewegung gegen Deutschland als Ausdruck jüdischer Solidarität. Hinter dieser Bewegung, so betonte er, stünden allein osteuropäische Juden.

Der Central Verein verfolgte mit Spannung die Aktivitäten der NaumannGruppe. Aus dem Bericht eines C.V.-Mitglieds über die Versammlung in Hanau sprechen Entrüstung und Entsetzen über Tenor und Wortwahl von Mautners Rede. Neben anderen Gehässigkeiten gibt der Berichterstatter Mautners Behauptungen wieder, osteuropäische Juden vergifteten das deutsche Judentum und steckten es mit ihrer Überheblichkeit an ${ }^{83}$. Das Referat Mautners sei von antisemitischen Ausdrükken wie „polnische Halunken", „ostjüdische Allüren“ und „unkultivierte Art" durchsetzt gewesen. Außerdem habe Mautner die Bedeutung antijüdischer Vorfälle in Deutschland heruntergespielt und behauptet, osteuropäische Juden verleumdeten „unsere tapfere SA“ ohne jede sachliche Grundlage, denn ihnen sei nichts Böses widerfahren, oder, in Mautners Worten: „Keinem Juden ist ein Haar gekrümmt worden." 84

Während des Referats waren, dem Bericht zufolge, eine stattliche Anzahl von SA-Männern in Uniform und Zivilkleidung sowie einige Mitglieder der NSDAP im Versammlungssaal anwesend, bei denen sich der Redner zur großen Entrüstung der C.V.-Mitglieder angebiedert hätte ${ }^{85}$. Stärker als der Wunsch des Central Vereins, sich schützend vor die osteuropäischen Juden zu stellen, war die Entrüstung unter den Mitgliedern und führenden Persönlichkeiten über den Versuch, den Status deutscher Juden unter dem neuen Regime durch Verunglimpfung der osteuropäischen Juden zu verbessern. Man war im Central Verein der Meinung, es ergebe sich „nicht bloß aus der rassenmäßigen Begründung der Behandlung der Judenfrage in Deutschland, sondern aus der Bewertung der entsprechenden Haltung durch die nationalsozialistische Presse“, wie wenig Zweck es habe, „sich von den Ostjuden zu distanzieren, auch wenn tausend $\mathrm{Mal}$ an sich Grund dafür vorläge" 86 . Die Nationalsozialisten verachteten sowohl den Central Verein als auch jede Körperschaft, die nicht erkannt habe, daß das jüdisch-deutsche Idyll beendet sei, und die sich weiterhin der deutschen Öffentlichkeit anbiedere und sie zufriedenstellen wolle.

Der Central Verein war stets darauf bedacht, Distanz zur Naumann-Gruppe zu wahren. Folgender Vorfall zeigt, daß es im wesentlichen das unterschiedliche Ver-

82 SoA, 721/1/1993, Hanauer Anzeiger, 17. 11. 1933.

83 SoA, 721/1/1993, Bericht über die Kundgebung der Nationaldeutschen Juden in Hanau, 16. 11.1933.

${ }^{84}$ SoA, 721/1/1993, An Rechtsanwalt Dr. Robert Rosenburg, Frankfurt a.M., 30. 11. 1933.

85 In den Berichten der C.V.-Mitglieder war es üblich, auf die Anwesenheit von Nationalsozialisten im Publikum hinzuweisen.

86 SoA, 721/1/1993, An Rechtsanwalt Dr. Robert Rosenburg, Frankfurt a.M., 30. 11. 1933. 
ständnis jüdischer Solidarität war, was den Central Verein von der NaumannGruppe trennte ${ }^{87}$ :

Das C.V.-Mitglied Norbert Deutsch stand in geschäftlichen Beziehungen zu einem nichtjüdischen Deutschen namens Schulz. Nachdem Schulz von der jüdischen Identität Norbert Deutschs erfahren hatte, verlor er das Interesse an diesen geschäftlichen Kontakten. Um Schulz zu einer Wiederaufnahme der Beziehungen zu überreden, verfaßte Deutsch einen Brief, in dem er sein „Deutschtum beteuerte“ und darauf hinwies, daß sein Vater als Frontkämpfer im Ersten Weltkrieg verwundet worden war. Er bat Schulz, doch zwischen den „schlechten verbrecherischen Menschen", die nach der Niederlage Deutschlands aus dem Osten gekommen seien, und denjenigen zu unterscheiden, die jederzeit ihre Pflicht dem Vaterland gegenüber erfüllt hätten. Schulz antwortete ablehnend und drohte, Deutschs jüdische Identität überall dort aufzudecken, wo Deutsch Geschäfte aufnehmen wolle. Als C.V.-Mitglied wandte Deutsch sich an den Central Verein mit der Bitte um Rat und Hilfe. Doch zu seiner großen Verwunderung wurde er abgewiesen und erhielt zudem eine Rüge. Der zuständige Referat des Central Vereins teilte ihm offen mit, daß ihn der übersandte Briefwechsel "nicht gerade angenehm berührt" habe. Vielmehr halte man es im Verein für selbstverständlich, daß er - Deutsch - die Ansicht, die er in diesen Bemerkungen zum Ausdruck bringe, bei nochmaliger Überlegung nicht aufrechterhalte. Der Verein halte es nicht für eine geeignete Methode, „sich selbst in ein günstiges Licht zu stellen dadurch, daß man andere herabsetzt". So verschaffe man sich weder Achtung noch Ansehen.

Aus derartigen Dokumenten wird deutlich, daß der Central Verein sich von allen Versuchen distanzierte, den Status deutscher Juden durch Verunglimpfung osteuropäischer Juden zu verbessern. Man hielt diese Strategie im Central Verein nicht nur für uneffektiv, sondern schätzte ein derartiges Verhalten auch als moralisch falsch ein.

Andererseits nun hielt der Central Verein an seiner Unterscheidung zwischen deutschen und nicht-deutschen Juden fest, welche auch in der Zeit vor dem Dritten Reich üblich gewesen war88; sie wurzelte tief in der Grundauffassung des Central Vereins und war letztlich stärker als die politischen Entwicklungen seit 1933. Trotz seiner moralischen Unterstützung osteuropäischer Juden in Deutschland bearbeitete der Central Verein praktisch ausschließlich Anfragen und Eingaben von Juden mit deutscher Staatsbürgerschaft. So konnte der Central Verein z.B. jüdische Händler unterstützen, die infolge des Boykotts jüdischer Geschäfte von den deutschen Märkten und Messen verdrängt worden waren, und erfolgreich eine Aufhebung der diskriminierenden Maßnahmen erreichen. Ebenso aktiv setzte er sich für den Schutz wandernder jüdischer Händler ein, die aus dem deutschen Landesverband der Händler und Reisenden ausgeschlossen worden waren ${ }^{89}$. Obwohl die Mehrheit der in diesen Wirtschaftssektoren erwerbstätigen Juden und damit die von

87 SoA, 721/1, 3422, Korrespondenz zwischen Norbert Deutsch und Dr. Weinberg vom Central Verein im Mai 1935.

88 So kümmerte sich der Central Verein 1925 um aus Polen geflohene Juden unter dem Hinweis, es handelte sich um Juden deutscher Herkunft, nicht um polnische Juden. SoA, 721/1/2093, Herr Hirschberg an Herrn Prediger Goldmann, 9. 9. 1925.

89 Verschiedene Ausgaben: SoA, 721/1/20, Informationsblatt des Mitteldeutschen Landesverbandes, Leipzig 1934. 
der nationalsozialistischen Diskriminierungspolitik in diesen Sektoren am stärksten Betroffenen osteuropäischer Herkunft waren, fühlte sich der Central Verein allein für Juden mit deutscher Staatsbürgerschaft zuständig90. Auch in der Behandlung von Staatenlosen unterschied er zwischen denjenigen, die in der Vergangenheit die deutsche Staatsbürgerschaft besessen hatten, und anderen Juden. Er beriet also nur jene Juden, denen die deutsche Staatsbürgerschaft abgesprochen worden war. In vielen Fällen waren dies Juden osteuropäischer Herkunft, denen ihre deutsche Staatsbürgerschaft infolge des Gesetzes über den Widerruf von Einbürgerungen vom 14. Juli 1933 aberkannt worden war. Staatenlose Juden, die niemals die deutsche Staatsbürgerschaft besessen hatten, wurden vom Central Verein nicht beraten $^{91}$. Er hielt also an der deutschen Staatsbürgerschaft als leitendem Kriterium für seine Arbeit fest, getreu seiner ursprünglichen Definition als Central Verein deutscher Staatsbürger jüdischen Glaubens. Hierbei übersah er, daß sich aufgrund der nationalsozialistischen Gesetzgebung die Grenzen zwischen deutschen und fremden Juden bereits auflösten.

Eine ähnliche Haltung legte der Reicbsbund jüdischer Frontsoldaten an den Tag. Es handelte sich hierbei um eine Organisation, die nach Ende des Ersten Weltkriegs mit der Zielsetzung gegründet worden war, die Kriegstradition und die Kameradschaft unter den jüdischen Kriegsveteranen in Deutschland zu pflegen ${ }^{92}$. Der Reichsbund glaubte, Kriegsdienst und Frontaufenthalt sicherten Gleichberechtigung und staatsbürgerliche Rechte. Diese Auffassung wurde ganz allgemein vertreten und auch auf Juden anderer Länder, darunter auch diejenigen Osteuropas, bezogen. In der Zeitschrift des Reichsbundes, Der Schild, konnte man Informationen über den Status jüdischer Frontsoldaten in der jüdischen Gesellschaft finden ${ }^{93}$, aber auch über die gesellschaftliche Anerkennung, die jüdischen Frontsoldaten in den Nachbarländern zuteil wurde94. Eine besondere Ehrung wurde den jüdischen Frontkämpfern Osteuropas auf ihrer Weltkonferenz 1935 zuteil, als in Anwesenheit des französischen Außenministers ein Denkmal für die im Kriege gefallenen Juden errichtet wurde 95 . Zur selben Zeit konzentrierte sich der Reichsbund eindeutig auf die Angelegenheiten deutscher Juden: Man widmete sich zwar der Betreuung von jüdischen Frontkämpfern, beschränkte sich dabei allerdings ausschließlich auf deutsche Staatsangehörige ${ }^{96}$.

Trotz eindeutiger Unterschiede gab es eine gemeinsame Linie zwischen der Naumann-Gruppe, dem Central Verein und dem Reichsbund jüdischer Frontsoldaten: Alle drei Organisationen weigerten sich, Grundprinzipien aufzugeben, die ihre je-

90 SoA, $721 / 1 / 35$.

91 So zum Beispiel die Antwort des Central Vereins in Berlin auf eine Anfrage in bezug auf Staatenlose: SoA, 721/1/2098, Friedländer (C.V. Berlin) an Landgerichtsrat a.D. Kurt Cohn, Chemnitz, 16. 1. 1934.

92 Zum Reichsbund jüdischer Frontsoldaten siehe: Dunker, Reichsbund.

93 Jüdische Frontkämpfer in Polen wiesen sich selbst eine zentrale Rolle im öffentlichen Leben und der jüdischen Erziehung in Polen zu, obwohl ihre Zahl relativ gering war: nur 6000. Der Schild, Die Haltung der jüdischen Frontkämpfer Polens, 14. Jg., Nr. 28, 12. 7. 1935.

94 Der Schild, Ein Denkmal für lettisch-jüdische Freiheitskämpfer, Der ungarische Freiheitskampf 1848/49 und die jüdischen Kämpfer, 14. Jg., Nr. 23, 7.6. 1935.

${ }_{95}$ Der Schild, Die Weltkonferenz jüdischer Frontsoldaten, 14. Jg., Nr. 25, 21. 6. 1935.

96 AAN, Amb Rp w Berlinie, Akt Nr. 907, Reichsbund jüdischer Frontsoldaten, Kriegsopferabteilung, Dr. Rosenthal an die polnische Gesandtschaft in Berlin am 10. 4. 1934. 
weilige Arbeit seit ihrer Gründung angeleitet hatten, und eine veränderte Grundhaltung einzunehmen, die den neuen politischen Verhältnissen entsprochen hätte: Der Verband Nationaldeutscher Juden hielt an seiner rassistischen Position fest, verunglimpfte osteuropäische Juden und betonte die Zugehörigkeit deutscher Juden zum deutschen Volke; der Central Verein gab den Begriff der Staatsbürgerschaft als Leitlinie und wesentliches Element der Zugehörigkeit nicht auf und beschränkte seine Arbeit ausschließlich auf Juden mit deutscher Staatsbürgerschaft; auch der Reichsbund jüdischer Frontsoldaten blieb seiner in der Zeit vor dem Nationalsozialismus verwurzelten Begrifflichkeit treu und dachte weiterhin, die Beteiligung an Krieg und Frontkampf auf deutscher Seite oder auf Seiten der deutschen Verbündeten im Ersten Weltkrieg erwirkten das Recht auf staatsbürgerliche Anerkennung, Status und Sicherheit in Deutschland. Der Reichsbund jüdischer Frontsoldaten hielt nach 1933 zudem weiterhin daran fest, daß dem gemeinsamen Frontkampf eine wichtige Rolle als verbindendes deutsch-jüdisches Identitätsmerkmal zukomme. Unter Hinweisen auf die „Blutopfer und Dienste für das Vaterland“ wandte sich der Reichsbund an deutsche Behörden mit der Bitte, die Rechte der deutsch-jüdischen Veteranenfamilien zu achten ${ }^{97}$. Reichsbund und Central Verein teilten den naiven Glauben, der Hinweis auf den Kriegsdienst in den Reihen der deutschen Armee könne langfristig einen Schutz vor den diskriminierenden Gesetzen der Nationalsozialisten gewähren. Der Dienst für Deutschland „im Krieg und im Frieden“ wurde vom Central Verein auch in seinem Bemühen betont, eine Aufhebung der deutschen Staatsbürgerschaft von Juden mit osteuropäischem Herkunftshintergrund zu verhindern ${ }^{98}$.

Das Festhalten an früheren Loyalitäten kam auch in der Haltung zum Ausdruck, die jüdische Organisationen im Hinblick auf die Stellung Deutschlands in der internationalen Öffentlichkeit einnahmen. Wie der Verband Nationaldeutscher Juden, zog der Reichsbund jüdischer Frontsoldaten, wenn auch mit gemäßigteren Worten, die deutsch-jüdische Solidarität einer innerjüdischen Solidarität vor. Infolge nationaldeutscher Loyalität wies der Reichsbund jeglichen Kommentar von Juden in aller Welt zu den Ereignissen in Deutschland ebenso zurück wie den Versuch, die jüdische Öffentlichkeit weltweit zugunsten der Juden in Deutschland und gegen den deutschen Staat zu mobilisieren. Daher widersetzte man sich in den Reihen des Reichsbunds auch der jüdischen Boykottbewegung 99 . Daß polnische Juden innerhalb dieser Bewegung eine aktive Rolle spielten, werden wir im weiteren Verlauf der Darstellung sehen.

Die Einstellung jüdischer Organisationen auf Reichsebene zu den Fragen der osteuropäischen Juden in Deutschland spiegelte in hohem Maße den Zeitgeist innerhalb der jüdischen Öffentlichkeit wider. Im Hinblick auf den Alltag der Juden in Deutschland war und blieb die jüdische Gemeinde der wesentliche Rahmen. Die Kräfteverhältnisse innerhalb der Gemeinden wirkten sich nun direkt auf die Lebensqualität osteuropäischer Juden in Deutschland aus. Die weitreichende Integration in die Gesellschaft der jeweiligen Umwelt, die für das Leben der Juden in Deutschland seit der Aufklärung so typisch gewesen war, hatte zwar, im Vergleich

97 BAK, R 43II600, Dr. Löwenstein an Hitler, 4. 4. 1933.

98 Gemeindeblatt Leipzig, Nr. 44, 2. 11. 1934.

99 Der Scbild, Zur 3. jüdischen Weltkonferenz, Nr. 33, 13. Jg., 31. 8. 1934. 
zu Gemeinden in den Ländern Osteuropas, die zentrale Position der jüdischen Gemeinden geschwächt. Doch hatten andere Faktoren den Status der Gemeinden auch angesichts von Integration und Assimilation gewahrt. Das deutsche Recht, das die Mitgliedschaft in der jüdischen Gemeinde mit der Zugehörigkeit zum Judentum gleichsetzte, hat ohne Zweifel zur Statusbildung jüdischer Gemeinden in Deutschland beigetragen.

Schon in der Weimarer Republik waren Status und Stärke der jüdischen Organisationen auf Gemeindeebene nicht mit den Verhältnissen auf Reichsebene dekkungsgleich. So leiteten z.B. die Zionisten zwischen 1927 und 1931 in einer Koalition die Berliner Gemeinde, also in einem Zeitraum, in dem eine derartige zionistische Repräsentation auf Reichsebene nicht denkbar gewesen wäre. Unterschiede zwischen den jüdischen Landesorganisationen und den regionalen Vertretungen existierten auch in Hinblick auf ideologische Auffassungen und Akzente der Arbeit. Während die Zionistische Vereinigung für Deutschland sich in erster Linie den zentralen Fragen zionistischer Politik und der Siedlung in Eretz Israel widmete und die "Gegenwartsarbeit" in den Gemeinden vernachlässigte, arbeiteten zionistische Aktivisten in den Gemeinden im Rahmen der Jüdischen Volkspartei an gesellschaftspolitischen Fragen und Problemen des Erziehungswesens sowie an der Stärkung der Position osteuropäischer Juden in Deutschland ${ }^{100}$. Auch im Central Verein gab es unterschiedliche Akzentsetzungen zwischen der Reichsorganisation, die sich zunehmend der zionistischen Bewegung öffnete und deren Mitglieder sich bisweilen den Reihen des Keren Hayessod, des Fonds zur jüdischen Besiedlung Palästinas, anschlossen, und den Aktivisten in den Gemeinden, die weiterhin im Zwist mit den Zionisten lagen 101 .

Traditionell traten zionistische Aktivisten in den Gemeinden für die Gleichberechtigung osteuropäischer Juden ein. Diese Unterstützung wurzelte in der prinzipiellen zionistischen Auffassung, das gemeinsame jüdische Schicksal fordere als obersten Wert die innerjüdische Solidarität. Auch die unter den Zionisten verbreiteten sozialistischen Auffassungen bedingten eine Hinwendung zu den sozial schwächeren Schichten und somit zu den osteuropäischen Juden. Diese war jedoch nicht frei von zweckgerichteten und pragmatischen Überlegungen. Die preußische Gesetzgebung von 1847 nämlich machte das Wahlrecht von der finanziellen Situation der Wähler und von der Dauer ihres Aufenthaltes in Deutschland abhängig. Auf dieses Gesetz berief sich die altansässige Judenheit, um den Einfluß osteuropäischer Juden in den Gemeinden einzuschränken. Die Zionisten wiederum, die cin großes Interesse an den osteuropäischen Juden als zukünftiges zionistisches Wählerpotential hatten, führten einen heftigen Kampf um die Verleihung des Wahlrechts an diese.

Ein von der Zionistischen Vereinigung für Deutschland Anfang 1936 verfaßter Bericht gibt Aufschluß über die Beziehungen zwischen Altansässigen und Zuge-

100 Brenner, Jüdische Volkspartei.

101 Zum Generationswechsel im Central Verein und dessen Haltung zum Zionismus in der ausgehenden Weimarer Republik siehe: Paucker, Der jüdische Abwehrkampf, S. $28 \mathrm{ff}$. - Zur Haltung der Mitglieder des Central Vereins zu Zionismus und Zionisten nach 1933 siehe: Margaliot, Political Reaction, S. 313-316. 
wanderten in den jüdischen Gemeinden ${ }^{102}$. In ganz Deutschland bestand demnach eine eindeutige Identifikation der altansässigen, etablierten Juden mit der liberalen Auffassung einerseits sowie der osteuropäischen Juden mit der zionistischen Bewegung andererseits. So konnte die Zionistische Vereinigung in Regionen und Gemeinden, in denen das etablierte Judentum dominierte - wie in der Pfalz, in Hannover und in kleinen Gemeinden in Sachsen, in Norddeutschland und im Rheinland -, nur sehr schwach Fuß fassen. Darüber hinaus stellt der Bericht fest, daß in den Regionen Deutschlands mit überwiegend altansässigen etablierten Juden nicht nur eine ablehnende Haltung dem Zionismus gegenüber zu verzeichnen war, sondern auch gegenüber osteuropäischen Juden als solchen. Diese ablehnende Haltung äußerte sich unter anderem in der Weigerung, osteuropäischen Juden gleiches Wahlrecht in den Gemeinden zu gewähren. So waren im Jahre 1936 in Hannover nur 2500 der insgesamt 4200 Juden auch wahlberechtigte Gemeindemitglieder. Noch schwieriger war die Situation in verschiedenen Gemeinden Sachsens, in denen die osteuropäischen Juden in der Überzahl waren, jedoch keine adäquate elektorale Vertretung erreichen konnten, da osteuropäische Juden kein Wahlrecht besaßen. In Leipzig, wo $75 \%$ der jüdischen Bevölkerung aus Osteuropa kamen, wurde der Kampf um die Wahlberechtigung noch in den dreißiger Jahren mit allerdings begrenztem Erfolg geführt. Ausländische Juden errangen zwar das passive Wahlrecht, doch das Wahlgesetz legte fest, daß mindestens 25 der insgesamt 33 Gemeinderatsmitglieder die deutsche Staatsbürgerschaft besitzen müßten ${ }^{103}$. Dieses Verfahren galt schon den Zeitgenossen als ungerecht. Noch viele Jahre später wurde diese Ungerechtigkeit in den Erinnerungen Leipziger Gemeindemitglieder erwähnt ${ }^{104}$.

Angesichts dieser Umstände darf es nicht verwundern, daß der Kampf um das Wahlrecht, dessen Anfänge in die Jahre vor dem Ersten Weltkrieg zurückreichen und der während der gesamten Weimarer Zeit andauerte, auch nach der Machtübernahme der Nationalsozialisten nicht eingestellt werden konnte. Für einen Teil jener Juden, die die massive Präsenz von osteuropäischen Juden in Deutschland fürchteten, wurden durch die Ereignisse der frühen dreißiger Jahre quasi ihre Vorahnungen wahr. Viele von ihnen assoziierten den gegen Ende des Ersten Weltkriegs erneut ausbrechenden Antisemitismus mit der „lästigen Anwesenheit" osteuropäischer Juden in Deutschland. Daher durfte man wohl kaum annehmen, daß ausgerechnet infolge der politischen Entwicklungen in Deutschland, die das jüdische Leben beispiellos veränderten, jene Kreise plötzlich bereit sein würden, osteuropäische Juden in stärkerem Maße zu integrieren. Der Verzicht auf ein begrenztes, gestaffeltes Wahlrecht zugunsten eines allgemeinen gleichen Wahlrechts hätte zudem einen Machtzuwachs der Zionisten gegenüber den liberalen jüdischen Organisationen bedeutet.

Im Grunde fehlte es innerhalb der liberalen jüdischen Organisationen, insbesondere in den Reihen des Central Vereins, an einer Vermittlung zwischen der grundsätzlichen Haltung auf Reichsebene und den Positionen der Aktivisten auf lokaler

102 CZA, Bericht der Zionistischen Vereinigung für Deutschland an den XXV. Delegiertentag in Berlin, 2.-4. Februar 1936.

103 Zur Situation der Leipziger Gemeinde existiert umfangreiches Material. Siehe zum Beispiel die von Nationalsozialisten durchgeführte Untersuchung: Arlt, Volksbiologische Untersuchungen; sowie die jüdischen Quellen: Aus Geschichte.

104 CAHJP, Sammlung Wolf 6607/d. 
Ebene. In der Führung des Central Vereins kam es nicht selten zur Kooperation mit der Zionistischen Vereinigung. Auf Reichsebene verhandelten der Central Verein und die Zionisten im Rahmen ihrer Debatten in der Reichsvertretung der deutschen $J u d e n$ über eine paritätische Repräsentation für Zionisten und Liberale. Der Kampf gegen das Wahlrecht von ausländischen Juden stand jedoch absolut im Gegensatz zum Paritätsprinzip und sollte die Machtposition der Zionisten schwächen. Er stand auch im Widerspruch zu der sich allmählich im Central Verein durchsetzenden Erkenntnis, daß die Diskriminierung osteuropäischer Juden der Situation der deutschen Juden im neuen Deutschland nicht zuträglich sein könne, ja daß vielmehr eine unsolidarische Haltung innerhalb des Judentums letztlich auf eine Verschlechterung der Lebensumstände aller Juden in Deutschland hinauslaufen werde. So blieb die hartnäckige Verweigerung gleichen Wahlrechtes für osteuropäische Juden in vielen Gemeinden der deutlichste und stärkste Ausdruck für diskriminierende Auffassungen und verwies auf tief verwurzelte Identitätsmerkmale vieler deutscher Juden, auf die im weiteren Verlauf ausführlicher eingegangen werden soll. 